\title{
Hematoporphyrin-ZnO Nanohybrids: Twin Applications in Efficient Visible-Light Photocatalysis and Dye-Sensitized Solar Cells
}

\author{
Soumik Sarkar, ${ }^{\dagger}$ Abhinandan Makhal, ${ }^{\dagger}$ Tanujjal Bora, ${ }^{\dagger}$ Karthik Lakhsman ${ }^{\ddagger}$ Achintya Singha, ${ }^{\nabla}$ \\ Joydeep Dutta, ${ }^{\ddagger} \S$ and Samir Kumar Pal ${ }^{\dagger} \dagger$
}

\begin{abstract}
${ }^{\dagger}$ Department of Chemical, Biological and Macromolecular Sciences, S. N. Bose National Centre for Basic Sciences, Block JD, Sector III, Salt Lake, Kolkata 700 098, India

${ }^{\ddagger}$ Centre of Excellence in Nanotechnology, School of Engineering and Technology, Asian Institute of Technology, Klong Luang, Pathumthani 12120, Thailand

${ }^{\S}$ Chair in Nanotechnology, Water Research Center, Sultan Qaboos University, PO Box 17, 123 Al-Khoudh, Sultanate of Oman

${ }^{\nabla}$ Department of Physics, Bose Institute, 93/1, Acharya Prafulla Chandra Road, Kolkata 700 009, India
\end{abstract}

\begin{abstract}
Light-harvesting nanohybrids (LHNs) are systems composed of an inorganic nanostructure associated with an organic pigment that have been exploited to improve the light-harvesting performance over individual components. The present study is focused on developing a potential LHN, attained by the functionalization of dense arrays of $\mathrm{ZnO}$ nanorods (NRs) with a biologically important organic pigment hematoporphyrin (HP), which is an integral part of red blood cells (hemoglobin). Application of spectroscopic techniques, namely, Fourier transform infrared spectroscopy (FTIR) and Raman scattering, confirm successful monodentate binding of $\mathrm{HP}$ carboxylic groups to $\mathrm{Zn}^{2+}$ located at the surface of $\mathrm{ZnO}$
\end{abstract} NRs. Picosecond-resolved fluorescence studies on the resulting

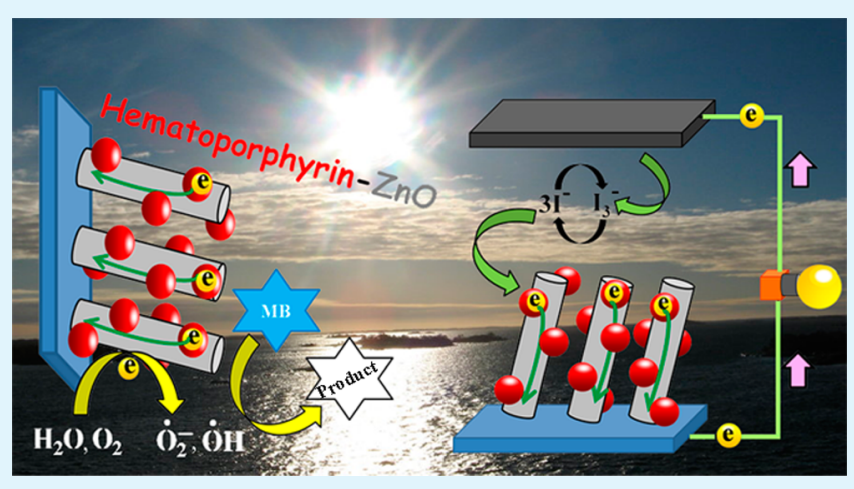
$\mathrm{HP}-\mathrm{ZnO}$ nanohybrid show efficient electron migration from photoexcited HP to the host ZnO NRs. This essential photoinduced event activates the LHN under sunlight, which ultimately leads to the realization of visible-light photocatalysis (VLP) of a model contaminant Methylene Blue (MB) in aqueous solution. A control experiment in an inert gas atmosphere clearly reveals that the photocatalytic activity is influenced by the formation of reactive oxygen species (ROS) in the media. Furthermore, the stable LHNs prepared by optimized dye loading have also been used as an active layer in dye-sensitized solar cells (DSSCs). We believe these promising LHNs to find their dual applications in organic electronics and for the treatment of contaminant wastewater.

KEYWORDS: hematoporphyrin, light-harvesting nanohybrids, photoinduced electron transfer, visible-light photocatalysis, reactive oxygen species, porphyrin-sensitized solar cell

\section{INTRODUCTION}

Light-harvesting nanohybrids (LHNs) are of intense current interest, as the simple search for individual nanoparticles no longer incites broad scientific interests for specific high-end applications. Most of these LHNs are composed of an inorganic nanostructure associated with an organic pigment. For example, association of a ruthenium-based sensitizing dye (SD) N719 with $\mathrm{TiO}_{2}$ or $\mathrm{ZnO}$ nanomaterials leads to very efficient LHNs for dye-sensitized solar cell (DSSC) applications. ${ }^{1-4}$ The cost, rarity, and environmental issues of ruthenium complexes limit their wide application and encourage exploration of lessexpensive, stable, and safer sensitizers. In this respect, porphyrin and porphyrin derivatives have shown promise for the replacement of ruthenium-based dyes for cost-effective and steady photovoltaic conversion of solar energy to electrical energy, because of their strong absorption in the region of $400-450 \mathrm{~nm}$ (B or Soret band) as well as $500-700 \mathrm{~nm}$ (Q bands). Several types of model porphyrins have been synthesized and their photophysical and electrochemical properties at the organic dye-semiconductor interface has been intensively studied. ${ }^{5-20}$ These reports have revealed that the efficiency of porphyrin-sensitized solar cells can be increased by adding donor groups to the porphyrin ring, attaching bulky substituents to the phenyl groups, or by introducing double or triple bonds between the porphyrin ring and the anchoring carboxylic group $(\mathrm{COOH})$. For example, Yalla et al. introduced long alkoxyl groups into the porphyrin ring and achieved an unprecedented $12.3 \%$ energy conversion efficiency in combination with a cobalt-based electrolyte and a complementary dye Y123. ${ }^{21}$ More recently, boron dipyrrome-

\footnotetext{
Received: October 11, 2012

Accepted: November 27, 2012

Published: November 27, 2012
} 
thene compound has been synthesized and coadsorbed on $\mathrm{TiO}_{2}$ nanoparticles with porphyrin dyes, which lead to a significant enhancement of energy conversion efficiency. ${ }^{11}$

Along with successful recognition of efficient DSSCs, harvesting solar energy has also attracted a lot of attention to reduce organic pollutants at very low concentration by means of visible-light photocatalysis (VLP). In both applications, the basic building block is a sensitizer, which absorbs visible light from the sun, thereby initiating electron migration upon photoexcitation. The decisive use of various sensitizers including quantum dots in the system is found to be one of the key considerations in the realization of resourceful LHNs for efficient electron migration from sensitizers to the nanoparticulate film of a wide-band-gap oxide semiconductor, and eventually the charge separation determines the VLP activity and the quality of DSSCs. ${ }^{22}$ In this respect, because of its large band gap $(3.3 \mathrm{eV})$, the popular photocatalyst $\mathrm{ZnO}$ can only utilize $\sim 4 \%$ of the incoming solar energy, thus restricting its practical applications in a model VLP process. Therefore, a visible-light-activated catalyst is desired that can take the benefit of utilizing a superior portion of the solar spectrum and would be much more effective in ecological cleanup. In the viewpoint of effective utilization of visible solar radiation, efforts have been made to trigger a photocatalyst under visible light by extending its photoresponse to the visible region by metal-ion doping, ${ }^{23}$ nonmetal doping, ${ }^{24,25}$ noble-metal deposition, ${ }^{26}$ narrow-bandgap semiconductors coupling, ${ }^{27-29}$ conducting polymer sensitization, ${ }^{30}$ and dye sensitization. ${ }^{31-33}$ In the latter approach, the excited dye molecule transfers an electron into the conduction band of the semiconductor, leading to the formation of a cationic radical of the dye. The injected electron then reacts with the dioxygen adsorbed on the surface of the metal oxide (MO), and generates active species involved in the process such as $\mathrm{O}_{2}{ }^{\bullet-}$ and dye $e^{\bullet+}$, as shown below:

$$
\begin{aligned}
& \text { dye }+h v \rightarrow \text { dye* } \\
& \text { dye }^{*}+\mathrm{MO} \rightarrow \text { dye }^{\bullet+}+\mathrm{MO}\left(\mathrm{e}_{\mathrm{CB}}^{-}\right) \\
& \mathrm{MO}\left(\mathrm{e}_{\mathrm{CB}}^{-}\right)+\mathrm{O}_{2} \rightarrow \mathrm{MO}+\mathrm{O}_{2}^{\bullet-} \\
& \text { dye } \\
& { }^{\bullet+}, \mathrm{O}_{2}^{\bullet-}+\mathrm{R} \rightarrow \text { product }
\end{aligned}
$$

The subsequent radical chain reactions lead to the degradation and mineralization of a contaminant ( $\mathrm{R}$ ) and concurrently water in the media acts as an electron donor to regenerate the sensitizer dye. ${ }^{33}$ For example, Zhao et al. has demonstrated a dye sensitization system incorporating Pt(dcbpy) $\mathrm{Cl}_{2}$ (dcbpy = 4,4'-dicarboxy-2,2'-bipyridine) on titania for the visible-light degradation of aqueous organic pollutant 4chlorophenol in the presence of $\mathrm{O}_{2} \cdot{ }^{31}$ Another study by Sun et al. has also demonstrated that aluminum phthalocyanine loaded on $\mathrm{TiO}_{2}$ is a good sensitizer for degradation of substituted phenols in aerated aqueous solution under visible-light irradiation. ${ }^{32}$ Although various organic-inorganic LHNs are found to be active for energy conversion, we come up with an approach to achieve both the eco-friendly VLP process and cost-effective DSSC with a model LHN.

In the first part of this work, a hydrothermally grown, vertically oriented $\mathrm{ZnO}$ nanorods (NRs) were sensitized with hematoporphyrin (HP), the first isolated porphyrin that came from the ejection of iron from protohemein and the hydration of the two vinyl side chains to form $\alpha$-hydroxyethyl groups in their place. To obtain a better understanding of the physical properties of HP-sensitized $\mathrm{ZnO}$ LHNs, we have analyzed the attachment of porphyrin molecules to $\mathrm{ZnO}$ surfaces by using FTIR and Raman spectroscopic studies. Upon the binding of $\mathrm{HP}$ on $\mathrm{ZnO}$ surfaces, the ultrafast charge transfer processes were investigated using steady-state and picosecond-resolved fluorescence techniques. After demonstrating $\mathrm{HP}-\mathrm{ZnO} \mathrm{LHN}$ as an efficient electron transfer mediator, we approached to employ the same nanohybrid in twin applications of efficient VLP process and to the fabrication of stable DSSCs. To the best of our knowledge, this sort of twin applications has not been reported previously by using a less-expensive, more stable, and safer $\mathrm{HP}-\mathrm{ZnO}$ nanohybrid. To implement this approach, it is essential that rates of heterogeneous electron transfer for the nanohybrid layer be characterized as a function of structural parameters, including surface hydrophilicity, molecular interactions, and nature of anchoring of the chromophores.

\section{EXPERIMENTAL SECTION}

Analytical-grade chemicals were used for synthesis without further purifications. Fluorine-doped tin oxide (FTO) conducting glass substrates, acquired from Asahi Glass Company, Japan, were cleaned by successive sonication with soap water, acetone, ethanol, and deionized (DI) water for $15 \mathrm{~min}$, each with adequate drying prior to their use.

2.1. Synthesis of $\mathrm{ZnO}$ NRs. Zinc acetate dihydrate, $\mathrm{Zn}$ $\left(\mathrm{CH}_{3} \mathrm{COO}\right)_{2} \cdot 2 \mathrm{H}_{2} \mathrm{O}$, Merck, zinc nitrate hexahydrate, $\mathrm{Zn}$ $\left(\mathrm{NO}_{3}\right)_{2} \cdot 6 \mathrm{H}_{2} \mathrm{O}$, Sigma-Aldrich, and hexamethylenetetramine, $\mathrm{C}_{6} \mathrm{H}_{12} \mathrm{~N}_{4}$, Aldrich, were used as the starting materials for a low temperature hydrothermal synthesis of $\mathrm{ZnO}$ NRs on FTO substrates. Detailed processes for the hydrothermal growth of single-crystalline $\mathrm{ZnO} \mathrm{NRs}$ are described in our previous reports. ${ }^{34-36}$ In brief, $\mathrm{ZnO}$ seed layers were initially deposited on cleaned FTO substrates by spray-pyrolysis method at $350{ }^{\circ} \mathrm{C}$ using $10 \mathrm{mM}$ zinc acetate aqueous solution. The seeded FTO substrates were then annealed in air at 350 ${ }^{\circ} \mathrm{C}$ for $1 \mathrm{~h}$ and used for the hydrothermal growth of the $\mathrm{ZnO}$ NRs. A 20-mM aqueous solution of zinc nitrate and hexamethylenetetramine was used as the precursor solution for the $\mathrm{ZnO} \mathrm{NR}$ growth, which was carried out at $90^{\circ} \mathrm{C}$ for $40 \mathrm{~h}$. This leads to the growth of $\mathrm{ZnO} N R s$ ca. $4-5 \mu \mathrm{m}$ in length and $100-200 \mathrm{~nm}$ in diameter. ${ }^{34,37}$ During the hydrothermal process, in order to maintain a constant growth rate of the $\mathrm{ZnO} \mathrm{NRs}$, the old precursor solution was replaced with a fresh solution in every $5 \mathrm{~h}$. The as-obtained $\mathrm{ZnO} \mathrm{NR}$ samples were then taken out of the reaction vessel and rinsed thoroughly with DI water thoroughly to remove unreacted residues. Finally, the samples were annealed in air at $350{ }^{\circ} \mathrm{C}$ for $1 \mathrm{~h}$ prior to the studies in this work.

2.2. Sensitization of HP Dyes on ZnO NR Surface. A $0.5 \mathrm{mM}$ $\mathrm{HP} \mathrm{C}_{34} \mathrm{H}_{38} \mathrm{~N}_{4} \mathrm{O}_{6}$ (Sigma) solution was prepared in anhydrous ethanol under constant stirring at room temperature for $12 \mathrm{~h}$. The sensitization of the $\mathrm{ZnO}$ NRs with HP dye was carried out in darkness and at room temperature by dipping the $\mathrm{ZnO} \mathrm{NR}$ samples into the prepared dye solution for $12 \mathrm{~h}$. After the sensitization process, the $\mathrm{ZnO}$ NRs were retracted from the dye solution, rinsed with anhydrous ethanol thoroughly (in order to remove any physisorbed dye molecules), and stored in darkness for further use. The same sensitization conditions were maintained to anchor $\mathrm{HP}$ on $\mathrm{ZnO}$ surface that was dispersed in ethanol for all the optical measurements.

2.3. Fabrication of DSSCs. For the fabrication of DSSCs, platinum NPs deposited on FTO substrates were used as counter electrodes. The platinum $(\mathrm{Pt}) \mathrm{NPs}$ were deposited on the FTO substrates by thermal decomposition of $5 \mathrm{mM}$ platinum chloride, $\mathrm{H}_{2} \mathrm{PtCl}_{6} \cdot \mathrm{H}_{2} \mathrm{O}$, Fluka (in isopropanol) at $385^{\circ} \mathrm{C}$ for $30 \mathrm{~min}$. The HPcoated $\mathrm{ZnO} \mathrm{NRs}$ were used as the photoelectrodes and the two electrodes were placed on top of each other with a single layer of 50$\mu$ m-thick Surlyn 1702 (Dupont) as a spacer between the two electrodes. A liquid electrolyte composed of $0.5 \mathrm{M}$ lithium iodide (LiI), $0.05 \mathrm{M}$ iodine $\left(\mathrm{I}_{2}\right)$, and $0.5 \mathrm{M}$ 4-tert-butylpyridine (TBP) in acetonitrile was used as the hole conductor and filled in the interelectrode space by using capillary force, through two small 
holes $($ diameter $=1 \mathrm{~mm})$ predrilled on the counter electrode. Finally, the two holes were sealed by using another piece of Surlyn, to prevent the leakage of electrolyte from the cell. In all our experiments, the active area of the DSSCs was fixed at $0.196 \mathrm{~cm}^{2}$.

2.4. Characterization Methods. A scanning electron microscopy (SEM) system (JEOL Model JSM-6301F, operating at $30 \mathrm{kV}$, working distance $=6.3 \mathrm{~mm}$, magnification $=50000 \times)$ was used to study the morphology of as-grown and HP-sensitized ZnO NRs. Powder X-ray diffraction (XRD) patterns were obtained by employing a scanning rate of $0.02^{\circ} \mathrm{s}^{-1}$ in the $2 \theta$ range from $25^{\circ}$ to $60^{\circ}$ by PANalytical XPERT-PRO diffractometer equipped with $\mathrm{Cu} \mathrm{K} \alpha$ radiation (at 40 $\mathrm{mA}, 40 \mathrm{kV}$ ). For optical experiments, the steady-state absorption and emission are determined with a Shimadzu UV-2450 spectrophotometer and a Jobin-Yvon Fluoromax-3 fluorimeter, respectively. All the photoluminescence transients were measured using the picosecond-resolved time-correlated single photon counting (TCSPC) technique, a commercially available picosecond diode laser-pumped (LifeSpec-ps) fluorescence spectrophotometer from Edinburgh Instruments, U.K. Picosecond excitation pulses from the picoquant diode laser were used at $409 \mathrm{~nm}$ with an instrument response function (IRF) of 60 ps. A microchannel-plate-photomultiplier tube (MCP-PMT, Hammamatsu) was used to detect the photoluminescence from the sample after dispersion through a monochromator. For all transients the polarizer on the emission side was adjusted to be at $55^{\circ}$ (the magic angle), with respect to the polarization axis of the excitation beam. Curve fitting of observed fluorescence transients were carried out using a nonlinear least-squares fitting procedure to the function

$$
X(t)=\int_{0}^{1} E\left(t^{\prime}\right) R\left(t-t^{\prime}\right) \mathrm{d} t^{\prime}
$$

which is comprised of convolution of the IRF $(E(t))$ with a sum of exponentials $\left(R(t)=A+\sum_{i=1}^{N} B_{i} \mathrm{e}^{-t / \tau_{i}}\right)$ with pre-exponential factors $\left(B_{i}\right)$, characteristic lifetimes $\left(\tau_{i}\right)$ and a background $(A)$. Relative concentration in a multiexponential decay is expressed as $c_{n}=\left(B_{n} /\right.$ $\left.\left(\sum_{i=1}^{N} B_{i}\right)\right) \times 100$. The average lifetime (amplitude-weighted) of a multiexponential decay ${ }^{38}$ is expressed as

$$
\tau_{\mathrm{av}}=\sum_{i=1}^{N} c_{i} \tau_{i}
$$

Changes in the water contact angle (WCA) on the $\mathrm{HP}-\mathrm{ZnO}$ surface was studied under normal room light $(0.2$ sun $)$ and 0.5 sun illumination conditions. For this purpose, $10 \mu \mathrm{L}$ of water was deposited dropwise on the $\mathrm{HP}-\mathrm{ZnO}$ substrates and using a digital microscope (Dino-Lite), the change in the WCA was continuously monitored for 10 min under both light conditions. Finally, the WCA after various illumination times was calculated by using Image J software.

2.5. Materials and Methods for the VLP Process. For the photocatalysis study, $\mathrm{ZnO}$ NRs were grown on glass substrates using microwave irradiation $(2.45 \mathrm{GHz})$ in a commercial microwave oven operated at low mode. Higher photocatalytic activity of the $\mathrm{ZnO}$ NRs grown by microwave-assisted hydrothermal process has been previously reported. ${ }^{39} \mathrm{~A} \mathrm{ZnO}$ nanoparticle seed layer was initially deposited on glass substrates using the same method mentioned in section 2.1. Under the microwave irradiation, $\mathrm{ZnO}$ NRs were grown for $4 \mathrm{~h}$ using $20 \mathrm{mM}$ aqueous solution of zinc nitrate and hexamethylenetetraamine. As obtained NRs were then rinsed with deionized water (DI) water several times and annealed at $250{ }^{\circ} \mathrm{C}$ in air for $1 \mathrm{~h}$. The sensitization of HP was carried out at room temperature, as described in section 2.2.

A 5- $\mu \mathrm{M}$ aqueous solution of $\mathrm{MB}$ was then prepared in DI water, which was used as the test contaminant for the photocatalysis test. A homemade flow-device consisting of two glass plates separated by a spacer was used to study the photocatalytic degradation of $\mathrm{MB}$; in which, one of the glass plates of the symmetric device contained the $\mathrm{ZnO}$ NRs sensitized with HP dyes. The as-prepared MB solution was then injected through the flow-device and the device placed under a 500-W tungsten-halogen lamp, which was used as the visible-light source in our study. The light was allowed to fall directly on the glass plate fabricated with $\mathrm{HP}-\mathrm{ZnO}$ LHNs and, to avoid the heat from the light source, a 20 -cm-thick water bath was placed between the light source and the flow device. The position of the device was then adjusted to receive an incoming light power of $75 \mathrm{~mW} / \mathrm{cm}^{2}$. After 30 min of continuous light irradiation, the photoproduct was collected from the flow device and its optical absorption spectrum was recorded to determine the percentage degradation $(\% \mathrm{DE})$ of $\mathrm{MB}$ using eq 1 :

$$
\% \mathrm{DE}=\frac{I_{0}-I}{I_{0}} \times 100
$$

where $I_{0}$ is the initial absorption intensity of $\mathrm{MB}$ at $\lambda_{\max }=664 \mathrm{~nm}$ and $I$ is the absorption intensity after $30 \mathrm{~min}$ of continuous photoirradiation.

The VLP process on MB in inert atmosphere was conducted in the similar way as described in the previous section using $\mathrm{ZnO}$ NRs sensitized with HP $(24 \mathrm{~h})$ as the catalyst media. Prior to the photocatalysis, argon (Ar) gas was passed through the MB solution for $30 \mathrm{~min}$. Similarly, Ar gas was also passed through the flow device for $30 \mathrm{~min}$ before injecting aqueous solution of MB. Finally, the solution was injected into the flow device and photocatalysis was conducted for $30 \mathrm{~min}$ at light intensity of $75 \mathrm{~mW} / \mathrm{cm}^{2}$. During the photocatalysis, Ar gas was purged through the flow device. After $30 \mathrm{~min}$, the degraded product from the flow device was collected and its optical absorption was measured to determine the percentage degradation of $\mathrm{MB}$ in inert atmosphere using eq 1 .

\section{RESULTS AND DISCUSSIONS}

3.1. Structural Characterization of HP-ZnO LHNs. Figure la shows the photographs of bare (left) and HP-

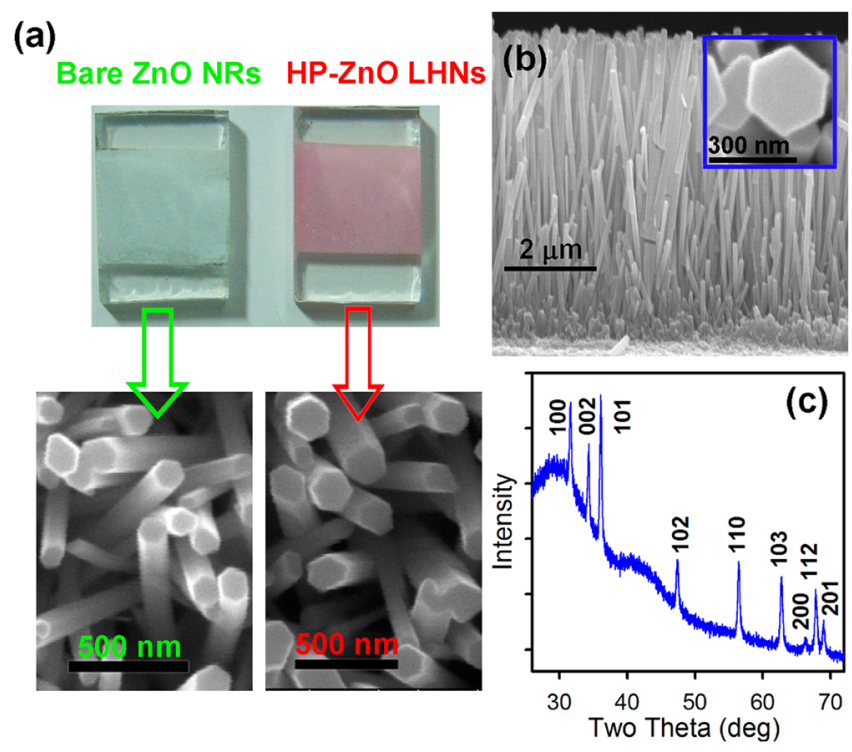

Figure 1. (a) Photographs of bare (left) and HP-sensitized (right) $\mathrm{ZnO}$ NRs decorated on FTO plates under daylight and their respective SEM images under the same experimental conditions. (b) Side-view and magnified top-view (inset) SEM images of vertically aligned, hexagonal $\mathrm{ZnO}$ NRs. (c) XRD pattern of as-prepared $\mathrm{ZnO}$ NRs.

sensitized (right) ZnO NRs decorated on FTO plates under daylight and their respective morphological characterization by SEM images are shown. The contrast difference is clearly noticeable from the two SEM images that were taken under the same experimental conditions for a fair comparison. The sideview SEM image (Figure 1b) indicates the formation of arrays of $\mathrm{ZnO} \mathrm{NRs}$ with a preferential growth direction along the polar facets in the [0002] direction of the $\mathrm{ZnO}$ hexagonal 
structure. The NRs growing perpendicular to the substrate are nearly uniform in length $(\sim 4-5 \mu \mathrm{m})$ and possess a characteristic hexagonal cross-section with a diameter of $\sim 180 \mathrm{~nm}$ (inset). On the basis of the XRD results (Figure 1c), the crystallographic phase of these $\mathrm{ZnO}$ NRs belongs to the wurtzite-type. ${ }^{40}$

3.2. Steady-State Absorption and PL Spectra of HP$\mathrm{ZnO}$ LHNs. The formation of $\mathrm{HP}-\mathrm{ZnO}$ nanohybrids are characterized by UV-vis spectroscopy. As shown in Figure 2a,
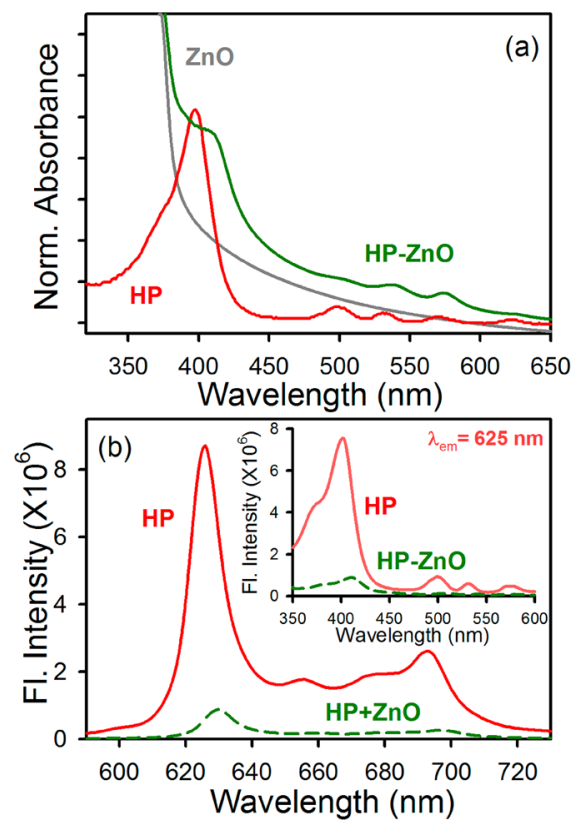

Figure 2. (a) UV-vis absorption spectra of $\mathrm{ZnO}$ NRs (gray), HP (red), and HP-ZnO LHNs (green) in ethanol. (b) Room-temperature PL spectra (excitation wavelength was at $409 \mathrm{~nm}$ ) of bare HP (red) and $\mathrm{ZnO}$-anchored HP (green) are shown. Inset shows the excitation spectra of HP monitored at $625 \mathrm{~nm}$.

$\mathrm{ZnO}$ NRs do not show considerable absorption above $410 \mathrm{~nm}$, but the optical absorption increases in the UV region down to $360 \mathrm{~nm}$, which reaches a plateau at $\sim 350 \mathrm{~nm}$. Bare HP exhibits a strong Soret absorption at $396 \mathrm{~nm}$, together with weak $\mathrm{Q}$ bands at $500 \mathrm{Q}_{y}(1 \leftarrow 0), 533 \mathrm{Q}_{y}(0 \leftarrow 0), 569 \mathrm{Q}_{x}(1 \leftarrow 0)$, and $622 \mathrm{~nm} \mathrm{Q} \mathrm{Q}_{x}(0 \leftarrow 0) .{ }^{41}$ In this respect, the removal of a metal ion from the center of a porphyrin molecule (which is the case in $\mathrm{HP}$ ) results in the appearance of these four weak bands in the visible region, which have been assigned to the splitting of doubly degenerate states into the vibration components. Relative to $\mathrm{HP}, \mathrm{HP}-\mathrm{ZnO}$ nanohybrid exhibits a $12-\mathrm{nm}$ bathochromic shift and a weaker intensity of the Soret band. ${ }^{42}$ These changes are obvious when compared to the absorption spectrum of $\mathrm{HP}$, and it is reasonable to conclude that $\mathrm{HP}-\mathrm{ZnO}$ LHNs are formed by the covalent binding of $\mathrm{ZnO}$ and anchoring groups of HP rather than only physical adsorption. As shown in Figure 2b, HP molecules are highly emissive as the photogenerated charge carriers undergo radiative recombination. Upon 409-nm laser excitation, the strong emission of HP was suppressed when anchored to $\mathrm{ZnO}$ NRs. The dramatic quenching of $\mathrm{HP}$ emission by $\mathrm{ZnO}$ NRs observed in the composite film is indicative of the fact that radiative decay becomes a minor pathway. The inset of Figure $2 \mathrm{~b}$ shows the excitation spectra of bare $\mathrm{HP}$ and $\mathrm{HP}-\mathrm{ZnO}$ LHNs monitored at the emission peak $(625 \mathrm{~nm})$. The excitation spectra of HP also show parallel maxima at 400 (Soret), 500, 532, and $574 \mathrm{~nm}$. In addition, the excitation spectra for $\mathrm{HP}-\mathrm{ZnO}$ LHNs also reveal an $\sim 12-\mathrm{nm}$ bathochromic shift that is in accordance with the observations made from the absorption spectra. Because of the interference of the absorption of $\mathrm{ZnO}$ NRs with the excitation wavelength of 409 $\mathrm{nm}$, it is difficult to obtain a quantitative estimate of HP emission quenching which was further established by monitoring the emission decay of HP and HP-ZnO LHNs.

3.3. Picosecond-Resolved Fluorescence Spectra of HP-ZnO LHNs. Using a picosecond-resolved fluorescence technique, we probed the excited-state interactions of $\mathrm{HP}-$ $\mathrm{ZnO}$ LHNs, which was prepared as discussed in section 2.2. As shown in Figure 3, the fluorescence decay curve of HP was

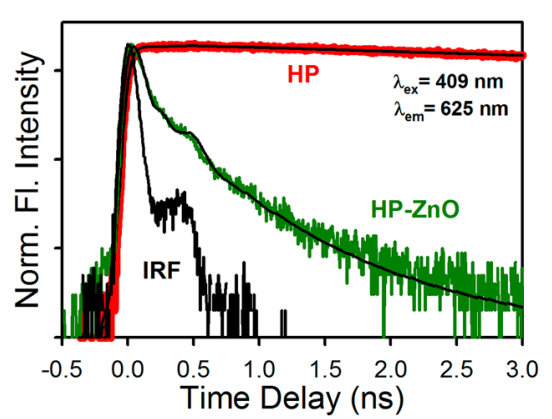

Figure 3. Fluorescence decay profiles of $\mathrm{HP}-\mathrm{ZnO}$ LHNs (green) and free HP (red) in ethanol.

fitted with single exponential decay, which showed a lifetime of $10.38 \pm 0.06$ ns depicting HP molecules were monomeric in ethanolic solution. ${ }^{9}$ A significant decrease in HP fluorescence lifetime $\left(\tau_{\text {avg }}\right)$ is observed in the presence of $\mathrm{ZnO}$ NRs and two fluorescence lifetimes are obtained, which are summarized in Table 1. In particular, a faster component of $0.05 \pm 0.01 \mathrm{~ns}$ generates which contributes nearly $97 \%$ of the decay in HP$\mathrm{ZnO}$ composite. Based on the results presented in Figures $2 \mathrm{~b}$ and 3, we can conclude that an additional nonradiative pathway competes with the fluorescence of excited HP molecules. The apparent rate constant $\left(k_{\mathrm{nr}}\right)$ is determined for the nonradiative processes by comparing the lifetimes of HP in the absence $\left(\tau_{0}\right)$ and the presence $(\tau)$ of $\mathrm{ZnO}$ NRs, using eq 2 .

$$
k_{\mathrm{nr}}=\frac{1}{\langle\tau\rangle}-\frac{1}{\left\langle\tau_{0}\right\rangle}
$$

The apparent rate constant for the nonradiative process is estimated to be $(1.66 \pm 0.24) \times 10^{10} \mathrm{~s}^{-1}$. As reported in previous studies, such $k_{\mathrm{nr}}$ values represent electron transfer from lowest unoccupied molecular orbital (LUMO) of HP to the conduction band of $\mathrm{ZnO}$ semiconductor and rules out the possibility of self-quenching due to the aggregation of $\mathrm{HP}$ molecules on $\mathrm{ZnO}$ surface. ${ }^{14,43,44}$ This indicates that the charge injection between excited $\mathrm{HP}$ and $\mathrm{ZnO} \mathrm{NRs}$ is an ultrafast process and it can be modulated by controlling the nature of anchoring of HP to the semiconductor surface.

3.4. FTIR Analysis of HP-ZnO LHNs. The dye used in this study, HP, contains two carboxylic groups, which possesses strong binding ability to the surface of $\mathrm{ZnO}$. Three possible binding modes have been previously proposed for the surface adsorption of carboxylate on metal oxides: ${ }^{45-47}$ (i) the monodentate (esterlike) linkage, (ii) bidentate chelating, and (iii) the bidentate bridging. Infrared vibrational spectroscopy 
Table 1. Dynamics of Picosecond-Resolved Luminescence Transients of HP and HP-ZnO LHNs ${ }^{a}$

$\begin{array}{lccrc}\text { sample } & \tau_{1}(\mathrm{~ns}) & \tau_{2}(\mathrm{~ns}) & \tau_{\text {avg }}(\mathrm{ns}) & k_{\mathrm{nr}}\left(\times 10^{10} \mathrm{~s}^{-1}\right) \\ \mathrm{HP}(\text { bare }) & & 10.38 \pm 0.06(100 \%) & 10.38 \pm 0.06 & \\ \mathrm{HP}-\mathrm{ZnO} & 0.05 \pm 0.01(97 \%) & 0.47 \pm 0.02(3 \%) & 0.06 \pm 0.01 & 1.66 \pm 0.24\end{array}$

${ }^{a_{T}}$ The emission (monitored at $625 \mathrm{~nm}$ ) was detected with $409-\mathrm{nm}$ laser excitation. $k_{\mathrm{nr}}$ represents nonradiative rate constant. Numbers in the parentheses indicate relative weightages.

usually provides a powerful tool to distinguish these binding modes. Generally, the frequency difference between the antisymmetric and symmetric stretching vibration $\left(\Delta=\nu_{\text {as }}-\right.$ $\left.\nu_{\mathrm{s}}\right)$ of carboxylate group is in the order of $\Delta$ (monodentate) > $\Delta($ ionic $) \approx \Delta$ (bridging $)>\Delta$ (bidentate $)$. For the pure dye, the stretching vibration band of carboxylic group is located at 1714 $\mathrm{cm}^{-1}$, as shown in Figure 4a. After coordinating to $\mathrm{ZnO}$ surface,
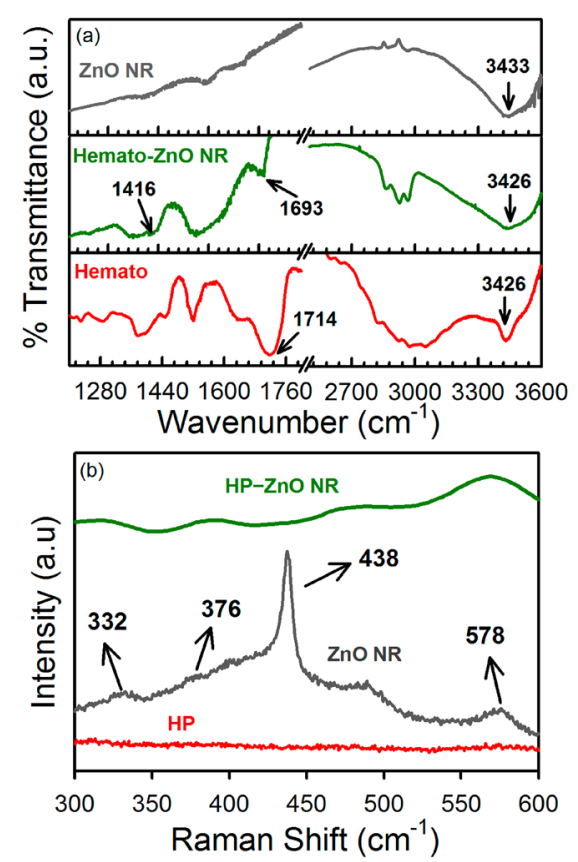

Figure 4. (a) FTIR and (b) Raman spectra of HP (red), ZnO NRs (gray), and $\mathrm{HP}-\mathrm{ZnO}$ LHNs (green).

this vibration band splits into two bands $\left(1693\right.$ and $1416 \mathrm{~cm}^{-1}$, respectively). The band located at $1693 \mathrm{~cm}^{-1}$ is ascribed to the antisymmetric stretching vibration of coordinated carboxylate group, while the shoulder band at $1416 \mathrm{~cm}^{-1}$ corresponds to the symmetric vibration. Therefore, the $\Delta$ value estimated for $\mathrm{HP}$ adsorbed on the pure $\mathrm{ZnO}$ is found to be $277 \mathrm{~cm}^{-1}$ (1693 $-1416=277 \mathrm{~cm}^{-1}$ ), which is a much larger value and suggests that the binding mode of $\mathrm{HP}$ on $\mathrm{ZnO}$ is dominantly the monodentate esterlike linkage. In a previous study, Zhao et al also reported monodentate binding of Rhodamine $\mathrm{B}$ dyes with $\mathrm{TiO}_{2}$ and $\mathrm{Al}(\mathrm{III})$-modified $\mathrm{TiO}_{2}$ nanoparticles, with a $\Delta$ value of 262 and $281 \mathrm{~cm}^{-1}$, respectively. ${ }^{48}$

3.5. Raman Spectra of HP-ZnO LHNs. The Raman spectra collected from $\mathrm{HP}, \mathrm{ZnO}$ NRs, and HP-ZnO LHNs in the wavenumber region of $300-600 \mathrm{~cm}^{-1}$ are shown in Figure $4 \mathrm{~b}$. As evidenced from the figure, HP molecules do not show an obvious peak in the experimental range. The Raman spectrum of the $\mathrm{ZnO} \mathrm{NR}$ arrays exhibits four vibration peaks at 332, 376, 438 , and $578 \mathrm{~cm}^{-1}$ thus indicating the presence of wurtzite structure. ${ }^{9,49}$ The peaks at 376 and $578 \mathrm{~cm}^{-1}$ correspond to the polar transverse $A_{1}$ and longitudinal $E_{1}$ optical phonon mode, respectively; the peak at $332 \mathrm{~cm}^{-1}$ is attributed to the $\mathrm{E}_{2}$ high $\mathrm{E}_{2}{ }^{\text {low }}$ mode; and the strong peak at $438 \mathrm{~cm}^{-1}$ can be assigned to the nonpolar optical phonon $\mathrm{E}_{2}$ mode of the $\mathrm{ZnO} \mathrm{NRs}$ at high frequency, which is associated with oxygen deficiency. ${ }^{9,50}$ After binding $\mathrm{HP}$ to $\mathrm{ZnO}$, the $\mathrm{E}_{2}$ mode characteristic band of $\mathrm{ZnO}$, associated to defect centers, is significantly perturbed. This is indicative of the passivation of $\mathrm{ZnO}$ surface states upon $\mathrm{HP}$ assembly. The presence of other characteristic bands indicates good retention of $\mathrm{ZnO}$ wurtzite structure and crystal shape during the sensitization of $\mathrm{ZnO}$ NRs with HP.

3.6. Visible-Light Photocatalysis of MB by $\mathrm{HP}-\mathrm{ZnO}$ LHNs. In order to apply our findings into a model application, we designed a flow device consisting of two glass plates (separated by a spacer), as illustrated in section 2.5. The research was aimed to clarify (1) the efficiency of the $\mathrm{HP}-\mathrm{ZnO}$ LHNs for the degradation of dye pollutants under visible-light irradiation, (2) the effect of dye-sensitization time on the degradation efficiency, and (3) the mechanism of catalytic enhancement of photodegradation of dye pollutants under visible irradiation. As dye-sensitized systems solely rely on trapped conduction band electrons to reduce dioxygen to superoxide, many dyes simply cannot survive this severe oxidative stress. $^{30-32,51-53}$ The optical response of the visiblelight source was found to be effective in the region of 420-950 $\mathrm{nm}$ with a maximum intensity at $620 \mathrm{~nm}$ (see Figure 5b, inset).
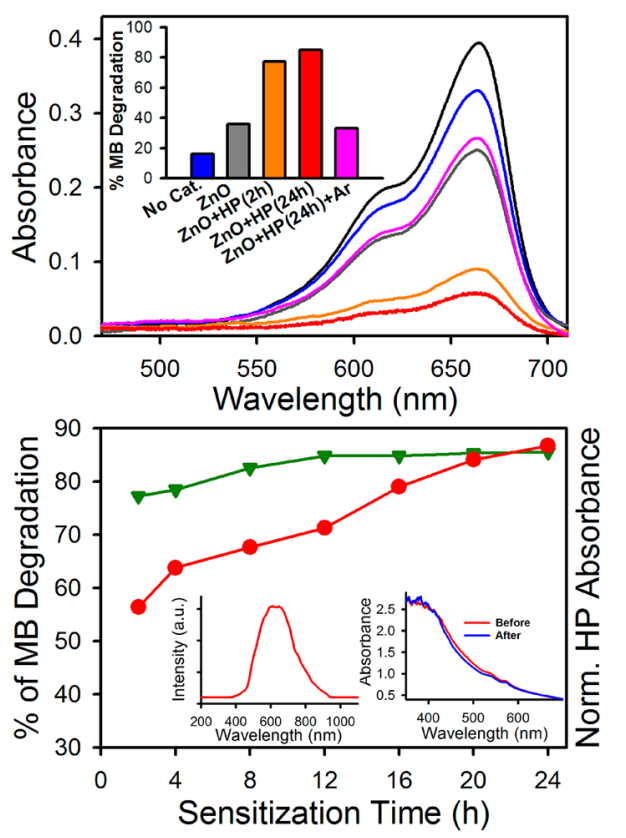

Figure 5. (a) UV-vis spectral changes of aqueous solution of $M B$ in the absence and the presence of $\mathrm{ZnO}$ and $\mathrm{HP}-\mathrm{ZnO}$ LHNs, under visible-light irradiation. (b) Dependence of photocatalytic activity on the dye-sensitization time (inset to the left shows the optical response of our visible light source, and inset to the right shows the absorbance of HP-sensitized $(24 \mathrm{~h}) \mathrm{ZnO}$ LHNs (on a quartz plate) before and after the photocatalysis process). 
The present work identifies a highly stable photocatalytic material $(\mathrm{HP}-\mathrm{ZnO})$, which promotes the visible-lightsensitized $(\lambda>420 \mathrm{~nm})$ decomposition of aqueous $\mathrm{MB}$, a representative organic pollutant, in the presence of air without the need for any undesirable sacrificial electron donors to promote regeneration of surface-bound sensitizer molecules. Figure 5a shows the change of absorption spectra of $\mathrm{MB}$ solution when exposed to visible light in the absence and presence of $\mathrm{ZnO} \mathrm{NRs}$ and $\mathrm{HP}-\mathrm{ZnO}$ LHNs at two extreme sensitization times, indicating the decolorization of $\mathrm{MB}$ during photoassisted reaction. The histogram (inset) clearly shows that degradation efficiency markedly enhanced in the presence of HP-ZnO LHNs, and it is also dependent on the HP sensitization time that reaches $\sim 85 \%$ after $24 \mathrm{~h}$ of $\mathrm{HP}$ sensitization.

In order to confirm that the $\mathrm{HP}-\mathrm{ZnO}$-induced VLP process occurs via the formation of reactive oxygen species (ROS), we performed $\mathrm{MB}$ photodegradation in an argon (Ar) atmosphere. Under deaerated conditions, a suppression of $\mathrm{O}_{2}^{-}$radical production occurs and the reducing action of $\mathrm{CB}$ electrons is decreased, because of the inhibition of the degradation efficiency of $\mathrm{HP}-\mathrm{ZnO}$ LHNs $(24 \mathrm{~h}$ ) from $85 \%$ to $33 \%$. In this respect, Sun and $\mathrm{Xu}$ had used $\mathrm{TiO}_{2}-$ aluminum phthalocyanine nanohybrids to degrade water pollutant 4chlorophenol where the catalyst capacity toward $\mathrm{O}_{2}$ adsorption in aqueous solution was found to be a predominant factor. ${ }^{32}$ For further understanding of the effect of dye-sensitization time on VLP activity, many $\mathrm{HP}-\mathrm{ZnO}$ substrates were prepared with different sensitization periods of $2,4,8,12,16,20$, and $24 \mathrm{~h}$. Figure $5 \mathrm{~b}$ shows that the absorption of $\mathrm{HP}-\mathrm{ZnO}$ LHNs is quite expectedly increased with increasing sensitization times, and the catalytic activity also increased due to the higher adsorption of sensitizing dye on $\mathrm{ZnO}$ surface which was found to be saturated after $12 \mathrm{~h}$ of sensitization time and remain constant thereafter. It is worth noting that the increment of HP concentration must lower the possibility of $\mathrm{MB}$ to attach to $\mathrm{ZnO}$ surface that would lead to a deterioration of degradation efficiency for increasing HP sensitization time. However, the reverse output again reveals that the bleaching process is followed by ROS formation that are generated at the $\mathrm{ZnO}$ surface and subsequently transported to the $\mathrm{MB}$ layer. Therefore, the remote bleaching is not a simple reduction of $\mathrm{MB}$ to its leuco form at the surface of $\mathrm{ZnO}$; rather, $\mathrm{MB}$ is probably oxygenated or decomposed. This sort of remote bleaching of $\mathrm{MB}$ in the gas phase is well-speculated in the literature. $^{54,55}$ In addition, we have verified the photostability of $\mathrm{HP}-\mathrm{ZnO}$ LHNs by measuring the absorbance of $\mathrm{HP}-\mathrm{ZnO}$ film (on a quartz plate) prior to and after the completion of photocatalysis reaction. As shown in the inset of Figure $5 b$, after passing $2 \mathrm{~mL}$ aqueous solution of $\mathrm{MB}$ through the flow device and $30 \mathrm{~min}$ of continuous light irradiation, it was found that a negligible amount of HP leached out from the quartz plate.

3.7. Water Contact-Angle Measurements on $\mathrm{HP}-\mathrm{ZnO}$ LHNs. The spreading of water on solid substrates is usually quantified through the contact angle, which positively characterizes the hydrophilicity and determines the biocompatibility of the materials. ${ }^{56}$ The contact angle measurements were done on $\mathrm{HP}-\mathrm{ZnO}$ films fabricated on a glass plate, under 0.5 sun and normal room-light intensity ( 0.2 sun). As shown in Figure 6, initially $\mathrm{HP}-\mathrm{ZnO}$ film shows a water contact angle of $129.1^{\circ}$, which gradually reduces with increasing time of irradiation. After $10 \mathrm{~min}$ of experimental time window, it is found that $\mathrm{HP}-\mathrm{ZnO}$ becomes more hydrophilic when

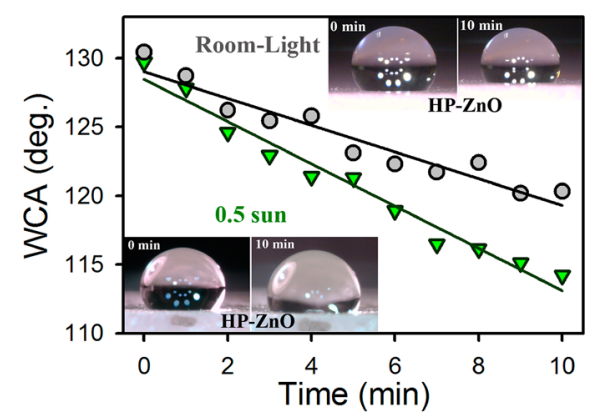

Figure 6. Water contact-angle measurements on $\mathrm{HP}-\mathrm{ZnO}$ modified substrates under the illumination of 0.5 sun and normal room light. Insets show their respective photographs.

irradiated under 0.5 sun illumination, compared to normal room light. This suggests that the electron-hole (e-h) pair generation occurs at a much faster rate when higher-intensity light is incident on the $\mathrm{HP}-\mathrm{ZnO}$ surface. Upon illumination, $\mathrm{HP}$ will inject electrons to the $\mathrm{ZnO}$ conduction band which may get trapped in the surface defect states (mainly oxygen vacancy centers) if there is no external force to sweep these electrons out. As a consequence, the surface trapped electrons will build up a hydrophilic surface until an equilibrium state of release is reached. Therefore, higher light intensity would facilitate the photocatalysis of a water contaminant in LHNs. The insets show their corresponding photographs.

3.8. Optimized DSSC Performance. Photoelectrochemical measurements ${ }^{37,57}$ were performed in a standard twocompartment cell, in acetonitrile containing $0.5 \mathrm{M} \mathrm{LiI}$ and 0.01 $\mathrm{M} \mathrm{I}_{2}$ as redox electrolyte and $\mathrm{FTO} / \mathrm{ZnO} / \mathrm{HP}$ as working electrode, while Pt/FTO was the counter electrode. Shown in Scheme 1 is the energy level alignment of $\mathrm{ZnO} \mathrm{NRs}$ and

Scheme 1. Schematic Energy Level Diagram and ElectronTransfer Path from Porphyrin Dyes to $\mathrm{ZnO}$

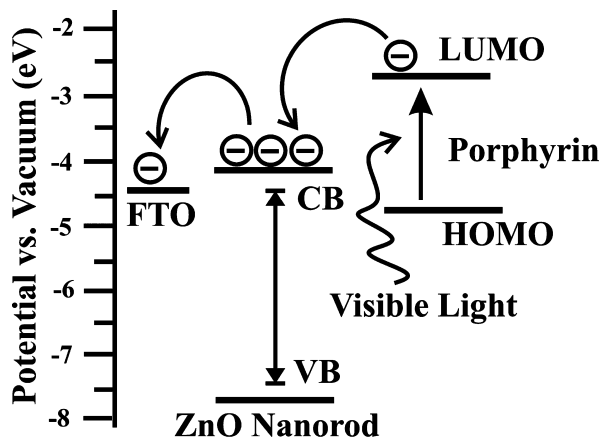

porphyrin dyes, to demonstrate the electron transfer pathway in the photocurrent system. Previous studies have estimated that the conduction band $(\mathrm{CB})$ and the valence band $(\mathrm{VB})$ of the $\mathrm{ZnO} \mathrm{NRs}$ are located at -4.2 and $-7.6 \mathrm{eV},{ }^{9}$ and the LUMO and the highest occupied molecular orbital (HOMO) of porphyrin dyes are located at approximately -2.75 and -4.75 eV, respectively. ${ }^{58,59}$ Upon visible-light irradiation, the electrons in $\mathrm{HP}$ molecules are injected to the $\mathrm{CB}$ of $\mathrm{ZnO}$ and consequently transported to the FTO plates, leading to a photocurrent. The photocurrent density-voltage $(J-V)$ curves of the devices measured under AM 1.5 irradiation $(100 \mathrm{~mW}$ $\mathrm{cm}^{-2}$ ) are shown in Figure $7 \mathrm{a}$, and the detailed photovoltaic parameters are summarized in Table 2. The fill factor (FF) and 

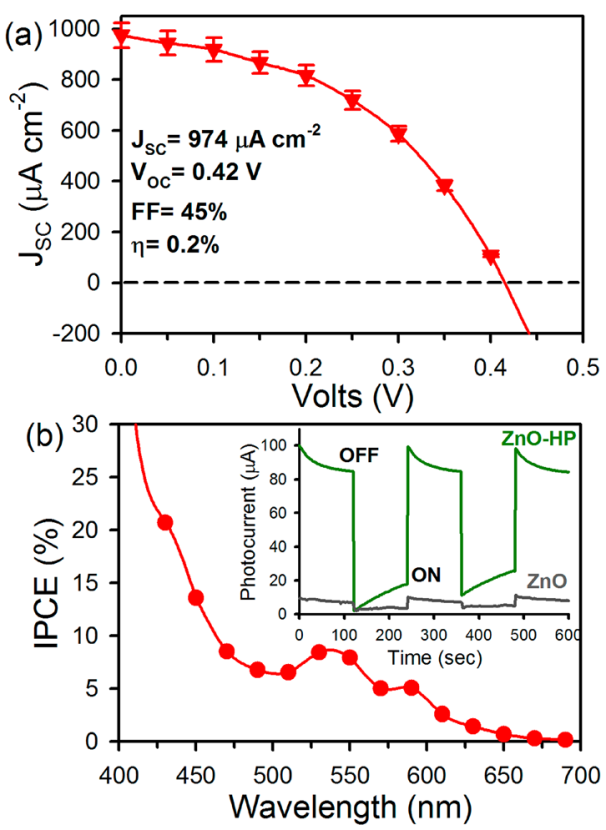

Figure 7. (a) Photocurrent-voltage $(J-V)$ characteristics and (b) incident photon-to-current conversion efficiency (IPCE) spectra for HP-sensitized $\mathrm{ZnO}$ NR-based DSSCs. Inset shows photocurrent responses of $\mathrm{ZnO} \mathrm{NRs}$ (gray) and $\mathrm{HP}-\mathrm{ZnO} \mathrm{LHN}$ (green) modified FTO electrode under the bias voltage of $2.5 \mathrm{~V}$. The photocurrent was measured across the thickness of the films with an incident power of $25 \mathrm{~mW} \mathrm{~cm}^{-2}$ from a halogen light source.

Table 2. Device Performance ${ }^{a}$ of the HP-Sensitized DSSCs

$\begin{array}{lcccc}\text { device } & V_{\mathrm{OC}}(\mathrm{V}) & \begin{array}{c}J_{\mathrm{SC}} \\ \left(\mu \mathrm{A} / \mathrm{cm}^{2}\right)\end{array} & \mathrm{FF}(\%) & \eta(\%) \\ \mathrm{HP}-\mathrm{ZnO} & 0.42 \pm 0.02 & 974 \pm 48 & 45 \pm 6 & 0.20 \pm 0.02 \\ \begin{array}{c}\mathrm{N} 719-\mathrm{ZnO} \\ \text { (control) }\end{array} & 0.69 \pm 0.05 & 620 \pm 33 & 30 \pm 5 & 0.13 \pm 0.01\end{array}$

${ }^{a}$ Short-circuit photocurrent densities $\left(J_{\mathrm{SC}} / \mathrm{cm}^{2}\right)$, open-circuit voltage $\left(V_{\mathrm{OC}}\right)$, fill factor $(F F)$, and efficiency $(\eta)$. The control experiment with a N719 dye-sensitized system is provided from our previous report (ref 37).

power conversion efficiency $(\eta)$ of the solar cells are determined from eqs 3 and 4:

$$
\begin{gathered}
\mathrm{FF}=\frac{V_{\mathrm{M}} J_{\mathrm{M}}}{V_{\mathrm{OC}} J_{\mathrm{SC}}} \\
\eta=\frac{V_{\mathrm{OC}} J_{\mathrm{SC}} \mathrm{FF}}{P_{\text {in }}}
\end{gathered}
$$

where $V_{\mathrm{M}}$ and $J_{\mathrm{M}}$ are the voltage and current density at the maximum power output, respectively, and $P_{\text {in }}$ is the intensity of the incident light $\left(100 \mathrm{~mW} \mathrm{~cm}^{-2}\right)$. The short-circuit photocurrent density $\left(J_{\mathrm{SC}}\right)$, open-circuit photovoltage $\left(V_{\mathrm{OC}}\right)$, and FF of a HP-sensitized cell with the iodine-based electrolyte are $\sim 974 \pm 48 \mu \mathrm{A} \mathrm{cm}{ }^{-2}, 0.42 \pm 0.02 \mathrm{~V}$, and $45 \% \pm 6 \%$, respectively, with an overall conversion efficiency $(\eta)$ of $0.20 \%$ $\pm 0.02 \%$. Note that a well-recognized ruthenium-based solar cell dye N719 provides $\eta$ of $0.13 \pm 0.01$ under the same experimental conditions, which is comparable with $\mathrm{HP}-\mathrm{ZnO}$ based DSSCs. ${ }^{37}$

The incident photon-to-current conversion efficiency (IPCE) for HP-sensitized DSSCs is shown in Figure 7b. The IPCE, which is defined as the number of electrons collected per incident photon, was evaluated from short-circuit photocurrent $\left(J_{\text {sc }}\right)$ measurements at different wavelengths $(\lambda)$, and the IPCE was calculated using eq 5 :

$$
\operatorname{IPCE}(\%)=\frac{1240 \times J_{S C}\left(\mathrm{~A} / \mathrm{cm}^{2}\right)}{\lambda(\mathrm{nm}) \times P\left(\mathrm{~W} / \mathrm{cm}^{2}\right)} \times 100
$$

where $P$ is the incident light power. The IPCE spectra are found to closely resemble the characteristic absorbance spectra of HP (Figure 2a), which exhibit peaks near 530 and $580 \mathrm{~nm}$, because of the $Q$ bands, and reaches a maximum value of $~ 30 \%$ at the Soret region $(\sim 400 \mathrm{~nm})$, signifying that the HP sensitizers on the photoanode surface are indeed responsible for photocurrent generation. In this respect, a recent study employed a noncovalent double-decker binding strategy to construct functional supramolecular single-wall carbon nanotubes-zinc porphyrin hybrids where a maximum of $12 \%$ IPCE has been achieved without any modification of porphyrin sidechains. $^{60}$

The photoconductivity measurements ${ }^{37,57,61}$ of bare $\mathrm{ZnO}$ and $\mathrm{HP}$-modified $\mathrm{ZnO}$ thin films are also performed in order to better understand the photocurrent response of the nanohybrids. At a fixed bias voltage of $5 \mathrm{~V}$, the photocurrent across the thickness of the films were measured by using FTO as one of the electrodes and a small (4-mm-diameter) drop of mercury $(\mathrm{Hg})$ on top of the film as a counter electrode. The light source (intensity $25 \mathrm{~mW} \mathrm{~cm}^{-2}$ ) was turned on and off every $20 \mathrm{~s}$, and the obtained current values were continuously recorded using a programmable multimeter (Gwinstek Model GDM-396). Inset of Figure $7 \mathrm{~b}$ shows the photocurrent response for the $\mathrm{ZnO} N R$ and $\mathrm{HP}-\mathrm{ZnO}$ thin films, where an improved photocurrent was observed for the HP-modified $\mathrm{ZnO}$ thin film $(\sim 100 \mu \mathrm{A})$ under illuminated condition compared to the bare $\mathrm{ZnO} \mathrm{NR}$ thin film $(\sim 10 \mu \mathrm{A})$.

\section{CONCLUSION}

In conclusion, hematoporphyrin (HP) has been conjugated onto covalently functionalized $\mathrm{ZnO} \mathrm{NRs}$, forming electron donor-acceptor $\mathrm{HP}-\mathrm{ZnO}$ nanohybrids, which are being established as potential light-harvesting materials, as represented in Scheme 2. The new hybrid nanomaterial has been methodically characterized with the aid of standard microscopic and optical techniques. The FTIR and Raman scattering studies confirm the formation of $\mathrm{HP}-\mathrm{ZnO}$ nanohybrid through the monodentate binding of $\mathrm{ZnO}$ and carboxylic groups of $\mathrm{HP}$ rather than simply physical adsorption. Steady-state and picosecond-resolved fluorescence measurements reveal efficient quenching of $\mathrm{HP}$ fluorescence in the $\mathrm{HP}-\mathrm{ZnO}$ nanohybrid, suggesting that photoinduced charge transfer takes place from LUMO of HP to the conduction band (CB) of $\mathrm{ZnO}$. Utilizing this phenomenon, a new dye-sensitized system, incorporating $\mathrm{HP}$ on $\mathrm{ZnO}$, is realized for the photodegradation of aqueous organic pollutants under visible-light irradiation. Finally, a photoelectrochemical cell is constructed based on HP sensitization onto nanostructured $\mathrm{ZnO}$ at fluorine-doped tin oxide (FTO) plates. The FTO/ $\mathrm{ZnO} / \mathrm{HP}$ electrode revealed prompt, stable and reproducible photocurrent and photovoltage, with incident photon-to-current conversion efficiency (IPCE) values as large as $30 \%$, without the application of bias voltage. The present work demonstrates the exciting potential of porphyrins as light-harvesting green dyes that can simultaneously be used in visible-light photocatalysis and 
Scheme 2. Schematic Representation of a Model LightHarvesting Nanohybrid (LHN) Depicting Covalently Functionalized ZnO NRs with Sensitizing Dye, Hematoporphyrin (HP) ${ }^{a}$
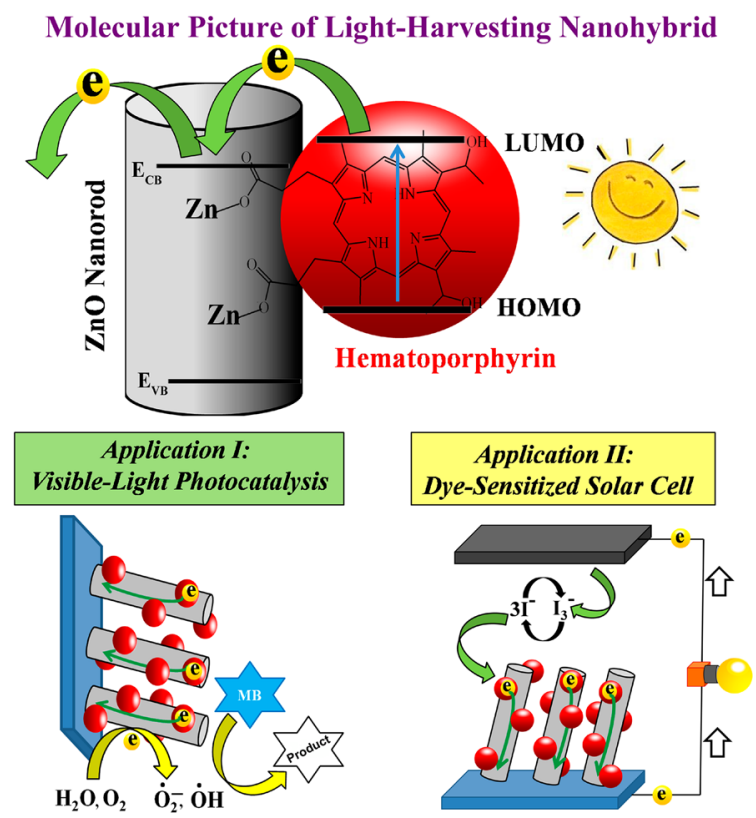

${ }^{a}$ The scheme illustrates the typical absorption process for visible light in the LHNs: light is absorbed by the sensitizing dye HP, transferring an electron into the conduction band $(\mathrm{CB})$ of $\mathrm{ZnO}$. The trapped electron in $\mathrm{ZnO}$ is exploiting dual vital applications of using $\mathrm{HP}-\mathrm{ZnO}$ nanohybrid as a model light-harvesting material: (I) visible-light photocatalysis and (II) dye-sensitized solar cell.

photovoltaics, and further work is underway in our laboratories to develop this.

\section{AUTHOR INFORMATION}

\section{Corresponding Author}

*E-mail: skpal@bose.res.in.

\section{Notes}

The authors declare no competing financial interest.

\section{ACKNOWLEDGMENTS}

S.S. thanks UGC (India) and A.M. thanks CSIR (India) for fellowships. We thank DST (India) for financial grants (No. DST/TM/SERI/2k11/103). T.B. thanks the Sheikh Saqr Al Qasimi Graduate Research Fellowship.

\section{REFERENCES}

(1) Chen, C. Y.; Wang, M.; Li, J. Y.; Pootrakulchote, N.; Alibabaei, L.; Ngoc-le, C.; Decoppet, J. D.; Tsai, J. H.; Grätzel, C.; Wu, C. G.; et al. ACS Nano 2009, 3, 3103-3109.

(2) Nazeeruddin, M. K.; Klein, C.; Liska, P.; Grätzel, M. Coord. Chem. Rev. 2005, 249, 1460-1467.

(3) Ku, C.; Wu, J. Appl. Phys. Lett. 2007, 91, 093117.

(4) Wanga, Z.; Kawauchib, H.; Kashimab, T.; Arakawa, H. Coord. Chem. Rev. 2004, 248, 1381-1389.

(5) Wang, C. L.; Lan, C. M.; Hong, S. H.; Wang, Y. F.; Pan, T. Y.; Chang, C. W.; Kuo, H. H.; Kuo, M. Y.; Diau, E. W. G.; Lin, C. Y. Energy Environ. Sci. 2012, 5, 6933-6940.

(6) Wu, S. L.; Lu, H. P.; Yu, H. T.; Chuang, S. H.; Chiu, C. L.; Lee, C. W.; Diau, E. W. G.; Yeh, C. Y. Energy Environ. Sci. 2010, 3, 949955.
(7) Lee, C. W.; Lu, H. P.; Lan, C. M.; Huang, Y. L.; Liang, Y. R.; Yen, W. N.; Liu, Y. C.; Lin, Y. S.; Diau, E. W. G.; Yeh, C. Y. Chem.-Eur. J. 2009, 15, 1403-1412.

(8) Drain, C. M.; Varotto, A.; Radivojevic, I. Chem. Rev. 2009, 109, $1630-1658$

(9) Tu, W.; Lei, J.; Wang, P.; Ju, H. Chem.—Eur. J. 2011, 17, 94409447.

(10) Liu, Y.; Zhang, Y.; Wang, S.; Pope, C.; Chen, W. Appl. Phys. Lett. 2008, 92, 143901.

(11) Shrestha, M.; Si, L.; Chang, C. W.; He, H.; Sykes, A.; Lin, C. Y.; Diau, E. W. G. J. Phys. Chem. C 2012, 116, 10451-10460.

(12) Campbell, W. M.; Jolley, K. W.; Wagner, P.; Wagner, K.; Walsh, P. J.; Gordon, K. C.; Schmidt-Mende, L.; Nazeeruddin, M. K.; Wang, Q.; Grätzel, M.; et al. J. Phys. Chem. C 2007, 111, 11760-11762.

(13) Wang, Q.; Campbell, W. M.; Bonfantani, E. E.; Jolley, K. W.; Officer, D. L.; Walsh, P. J.; Gordon, K.; Humphry-Baker, R; Nazeeruddin, M. K.; Gratzel, M. J. Phys. Chem. B 2005, 109, 15397-15409.

(14) Saarenpaa, H.; Sariola-Leikas, E.; Perros, A. P.; Kontio, J. M.; Efimov, A.; Hayashi, H.; Lipsanen, H.; Imahori, H.; Lemmetyinen, H.; Tkachenko, N. V. J. Phys. Chem. C 2012, 116, 2336-2343.

(15) Xu, Y.; Liu, Z.; Zhang, X.; Wang, Y.; Tian, J.; Huang, Y.; Ma, Y.; Zhang, X.; Chen, Y. Adv. Mater. 2009, 21, 1275-1279.

(16) Pagona, G.; Zervaki, G. E.; Sandanayaka, A. S. D.; Ito, O.; Charalambidis, G.; Hasobe, T.; Coutsolelos, A. G.; Tagmatarchis, N. J. Phys. Chem. C 2012, 116, 9439-9449.

(17) Gong, X.; Milic, T.; Xu, C.; Batteas, J. D.; Drain, C. M. J. Am. Chem. Soc. 2002, 124, 14290-14291.

(18) Abdul, S. A.; Cui, J. B. J. Phys. Chem. C 2012, 116, 9433-9438.

(19) Subbaiyan, N. K.; Maligaspe, E.; D’Souza, F. ACS Appl. Mater. Interfaces 2011, 3, 2368-2376.

(20) Stromberg, J. R.; Marton, A.; Kee, H. L.; Kirmaier, C.; Diers, J. R.; Muthiah, C.; Taniguchi, M.; Lindsey, J. S.; Bocian, D. F.; Meyer, G. J.; et al. J. Phys. Chem. C 2007, 111, 15464-15478.

(21) Yella, A.; Lee, H. W.; Tsao, H. N.; Yi, C.; Chandiran, A. K.; Nazeeruddin, M. K.; Diau, W. G. E.; Yeh, C. Y.; Zakeeruddin, S. M.; Grätzel, M. Science 2011, 334, 629-634.

(22) Zhao, L.; Hu, L.; Fang, X. Adv. Funct. Mater. 2012, 22, 15511566.

(23) Chen, C. C.; Li, X. Z.; Ma, W. H.; Zhao, J. C.; Hidaka, H.; Serpone, N. J. Phys. Chem. B 2002, 106, 318-324.

(24) Asahi, R.; Morikawa, T.; Ohwaki, T.; Aoki, K.; Taga, Y. Science 2001, 293, 269-271.

(25) Lu, N.; Quan, X.; Li, J.; Chen, S.; Yu, H.; Chen, G. J. Phys. Chem. C 2007, 111, 11836-11842.

(26) Li, X. Z.; Li, F. B. Environ. Sci. Technol. 2001, 35, 2381-2387.

(27) Zhang, Z.; Wang, W.; Wang, L.; Sun, S. ACS Appl. Mater. Interfaces 2012, 4, 593-597.

(28) Jiang, J.; Zhang, X.; Sun, P.; Zhang, L. J. Phys. Chem. C 2011, $115,20555-20564$.

(29) Li, G. S.; Zhang, D. Q.; Yu, J. C. Environ. Sci. Technol. 2009, 43, $7079-7085$

(30) Zhang, H.; Zong, R. L.; Zhao, J. C.; Zhu, Y. F. Environ. Sci. Technol. 2008, 42, 3803-3807.

(31) Zhao, W.; Sun, Y.; Castellano, F. N. J. Am. Chem. Soc. 2008, 130, $12566-12567$.

(32) Sun, Q.; Xu, Y. J. Phys. Chem. C 2009, 113, 12387-12394.

(33) Bae, E.; Choi, W. Environ. Sci. Technol. 2003, 37, 147-152.

(34) Baruah, S.; Dutta, J. J. Cryst. Growth 2009, 311, 2549-2554.

(35) Baruah, S.; Dutta, J. J. Sol-Gel Sci. Technol. 2009, 50, 456-464.

(36) Fang, X.; Hu, L.; Ye, C.; Zhang, L. Pure Appl. Chem. 2010, 82, 2185-2198.

(37) Sarkar, S.; Makhal, A.; Lakshman, K.; Bora, T.; Dutta, J.; Pal, S. K. J. Phys. Chem. C 2012, 116, 14248-14256.

(38) Lakowicz, J. R. Principles of Fluorescence Spectroscopy, 2nd Edition; Kluwer Academic/Plenum: New York, 1999.

(39) Baruah, S.; Mahmood, M. A.; Myint, M. T. Z.; Bora, T.; Dutta, J. Beilstein J. Nanotechnol. 2010, 1, 14-20.

(40) Liu, B.; Zeng, H. C. J. Am. Chem. Soc. 2003, 125, 4430-4431. 
(41) Srivastava, R. C.; Anand, V. D.; Carper, W. R. Appl. Spectrosc. 1973, 27, 444-449.

(42) Castillero, P.; Sanchez-Valencia, J. R.; Cano, M.; Pedrosa, J. M.; Roales, J.; Barranco, A.; Gonzalez-Elipe, A. R. ACS Appl. Mater. Interfaces 2010, 2, 712-721.

(43) Hasobe, T.; Saito, K.; Kamat, P. V.; Troiani, V.; Qui, H.; Solladie, N.; Kim, K. S.; Park, J. K.; Kim, D.; D’Souza, F.; et al. J. Mater. Chem. 2007, 17, 4160-4170.

(44) Cheng, H. M.; Hsieh, W. F. Nanotechnology 2010, 21, 485202.

(45) Weng, Y. X.; Li, L.; Liu, Y.; Wang, L.; Yang, G. Z. J. Phys. Chem. B 2003, 107, 4356-4363.

(46) Boettcher, S. W.; Bartl, M. H.; Hu, J. G.; Stucky, G. D. J. Am. Chem. Soc. 2005, 127, 9721-9730.

(47) Deacon, G. B.; Phillips, R. J. Coord. Chem. Rev. 1980, 33, 227250.

(48) Zhao, D.; Chen, C.; Wang, Y.; Ma, W.; Zhao, J.; Rajh, T.; Zang, L. Environ. Sci. Technol. 2008, 42, 308-314.

(49) Zhang, Y.; Jia, H.; Wang, R.; Chen, C.; Luo, X.; Yu, D.; Lee, C. Appl. Phys. Lett. 2003, 83, 4631-4633.

(50) Jiang, P.; Zhou, J. J.; Fang, H. F.; Wang, C. Y.; Wang, Z. L.; Xie, S. S. Adv. Funct. Mater. 2007, 17, 1303-1310.

(51) Liang, H. C.; Li, X. Z. Appl. Catal., B 2009, 86, 8-17.

(52) Wang, D. S.; Zhang, J.; Luo, Q. Z.; Li, X. Y.; Duan, Y. D.; An, J. J. Hazard. Mater. 2009, 169, 546-550.

(53) Chen, C.; Zhao, W.; Li, J.; Zhao, J.; Hidaka, H.; Serpone, N. Environ. Sci. Technol. 2002, 36, 3604-3611.

(54) Tatsuma, T.; Tachibana, S. I.; Miwa, T.; Tryk, D. A.; Fujishima, A. J. Phys. Chem. B 1999, 103, 8033-8035.

(55) Tatsuma, T.; Tachibana, S.; Fujishima, A. J. Phys. Chem. B 2001, 105, 6987-6992.

(56) Liu, Y.; Lin, Z.; Lin, W.; Moon, K. S.; Wong, C. P. ACS Appl. Mater. Interfaces 2012, 4, 3959-3964.

(57) Sarkar, S.; Makhal, A.; Bora, T.; Baruah, S.; Dutta, J.; Pal, S. K. Phys. Chem. Chem. Phys. 2011, 13, 12488-12496.

(58) Liu, D.; Wu, W.; Qiu, Y.; Yang, S.; Xiao, S.; Wang, Q. Q.; Ding, L.; Wang, J. Langmuir 2008, 24, 5052-5059.

(59) Kee, H. L.; Kirmaier, C.; Tang, Q.; Diers, J. R.; Muthiah, C.; Taniguchi, M.; Laha, J. K.; Ptaszek, M.; Lindsey, J. S.; Bocian, D. F.; et al. Photochem. Photobiol. 2007, 83, 1125-1143.

(60) Sandanayaka, A. S. D.; Subbaiyan, N. K.; Das, S. K.; Chitta, R.; Maligaspe, E.; Hasobe, T.; Ito, O.; D’Souza, F. Chem. Phys. Chem. 2011, 12, 2266-2273.

(61) Hu, L.; Yan, J.; Liao, M.; Xiang, H.; Gong, X.; Zhang, L.; Fang, X. Adv. Mater. 2012, 24, 2305-2309. 